\title{
Circularity of the foveal avascular zone and its correlation with parafoveal vessel density, in subjects with and without diabetes
}

\author{
Circularidad de la zona avascular foveal y su correlación con la densidad vascular \\ parafoveal, en sujetos con y sin diabetes
}

\author{
Selma A. Somilleda-Ventura1', Dulce M. Razo-Blanco-Hernández², Jesús A. Reyes-Calderón ${ }^{3}$, \\ Guillermo M. Ceballos-Reyes ${ }^{1}$ and Virgilio Lima-Gómez ${ }^{*}$ \\ ${ }^{1}$ Postgraduate and Research Studies Section, Superior School of Medicine, National Polytechnic Institute, Mexico City, Mexico; ${ }^{2}$ Research Division, \\ Hospital Juárez de México, Mexico City, Mexico; ${ }^{3}$ Ophthalmology Service, Hospital Juárez de México, Mexico City, Mexico
}

\begin{abstract}
Purpose: To characterize the distribution of the foveal avascular zone circularity and its correlation with parafoveal vessel density, in subjects with and without diabetes. Methods: Observational, descriptive, cross-sectional, and prospective study; subjects without diabetes (Group 1), with diabetes without retinopathy (Group 2), or with diabetic retinopathy (Group 3) were included. Means of foveal avascular zone circularity and parafoveal vessel density were compared between groups (Kruskal-Wallis) and their correlation was calculated with Spearman's Rho test. Results: Seventy-seven eyes; central vessel density mean was higher in Group 1 than in Group 2 and higher in Group 2 than in Group 3; inner and complete vessel density means were also higher in Group 2 than in Group 3. The mean of the foveal avascular zone circularity did not differ between groups, and in Group 3 it had a positive correlation with central (0.45), inner (0.56), and complete (0.53) vessel densities. Conclusions: Circularity does not differ between subjects with diabetes, with and without retinopathy, and has only a low correlation with parafoveal vessel density in people with diabetic retinopathy, which does not allow anticipating a reduction of vessel density in this disease.
\end{abstract}

KEY WORDS: Circularity. Diabetes mellitus. Diabetic retinopathy. Foveal avascular zone. Parafoveal vessel density.

\section{Resumen}

Objetivo: Caracterizar la distribución de la circularidad de la zona avascular foveal y su correlación con la densidad vascular perifoveal, en sujetos con y sin diabetes. Método: Estudio observacional, descriptivo, transversal y prospectivo; se incluyeron sujetos sin diabetes (Grupo 1), con diabetes sin retinopatía (Grupo 2) y con retinopatía diabética (Grupo 3). Los promedios de circularidad de la zona avascular foveal y de la densidad vascular parafoveal se compararon entre grupos (Kruskal-Wallis), y se calculó su correlación mediante la prueba Rho de Spearman. Resultados: Se estudiaron 77 ojos. El promedio de la densidad vascular central fue mayor en el Grupo 1 que en el Grupo 2, y mayor en el Grupo 2 que en el Grupo 3. Los promedios de la densidad vascular interna y completa también fueron mayores en el Grupo 2 que en el Grupo 3. El promedio de la circularidad de la zona avascular foveal no difirió entre grupos, y en el Grupo 3 tuvo una correlación positiva con la densidad vascular central (0.45), interna (0.56) y completa (0.53). Conclusiones: La circularidad no difiere entre sujetos con y sin diabetes, con y sin retinopatía, y solo tiene una baja correlación con la densidad vascular parafoveal en sujetos con retinopatía diabética, lo cual no permite anticipar una reducción de la densidad vascular en esta enfermedad.

PALABRAS CLAVE: Circularidad. Densidad vascular parafoveal. Diabetes mellitus. Retinopatía diabética. Zona avascular foveal.

\author{
Correspondence: \\ *Virgilio Lima-Gómez \\ Av. Instituto Politécnico Nacional \\ C.P. 5160, Mexico City, Mexico \\ E-mail: forscher7@gmail.com
}

Date of reception: 26-03-2018

Date of acceptance: 11-05-2018

DOI:10.24875/CIRU.18000638
Cir Cir. 2019;87:390-395

Contents available at PubMed www.cirugiaycirujanos.com 


\section{Background}

Diabetic retinopathy, a chronic and specific complication of diabetes ${ }^{1}$, is the main cause of blindness in the working-age population worldwide ${ }^{2}$. The alteration that most commonly causes visual loss in this disease is macular edema, a thickening at the area of maximum vision in the retina, which damages photoreceptors and reduces visual acuity ${ }^{3}$; its timely treatment allows to reduce thickening and, in some cases, improve visual acuity ${ }^{4}$.

A feature that can prevent visual recovery after treatment is the damage to the capillary network surrounding the fovea, the zone with the highest resolution in the macula where there are no blood vessels ${ }^{5}$; this region, known as the foveal avascular zone, enlarges in the presence of capillary closure and ischemia $^{6}$, a condition that affects up to $7 \%$ of people with diabetic retinopathy ${ }^{7}$. The foveal avascular zone can be outlined by a fluorescein retinal angiography ${ }^{8}$, and currently with optical coherence tomography devices, which generate what is known as optical coherence tomography angiography (OCTA); this study provides other data such as parafoveal vessel density, the perimeter of the foveal avascular zone, and its circularity ${ }^{9}$.

The circularity is the similarity that the shape of the foveal avascular zone has with a circle, as calculated with the formula: circularity $=4 \pi \mathrm{A} / \mathrm{P} 2$, where $\mathrm{A}$ is the area and $P$ the perimeter of the foveal avascular zone; it becomes irregular when capillary closure exists, which reduces the circularity. The value of this variable comes along with the report of parafoveal vessel density, and it could be useful to identify an early reduction of this, particularly in center-involving macular edema, because retinal thickening changes the measurement level and limits the quantification of vessel density.

In our population, the characteristics of the foveal avascular zone circularity are unknown, which limits its application to detect cases with capillary loss. A study was conducted to determine the distribution of the foveal avascular zone circularity and its correlation with parafoveal vessel density, in subjects with and without diabetes.

\section{Methods}

This was an observational, descriptive, cross-sectional, and prospective study in subjects treated at a federal hospital in Mexico City. The Institutional Review Board of the hospital authorized the study, which adhered to the tenets of the Declaration of Helsinki; all the participants signed an informed consent before their evaluation.

Inclusion criteria were: subjects of any gender, aged 40-70 years, without diabetes or with Type 2 diabetes, without retinopathy or with mild or moderate diabetic retinopathy. Subjects with any other retinal diseases, previous intraocular surgeries, lens opacities, or any condition that prevented the acquisition of an angiotomographic image of adequate quality were excluded; elimination criteria were withdrawal of the informed consent and the presence of macular ischemia, which was operationally defined as an area of the foveal avascular zone that exceeded by two standard deviations (SD), the mean reported in eyes with non-proliferative diabetic retinopathy $\left(0.62 \mathrm{~mm}^{2}\right)^{10}$.

The sample was divided into three groups: subjects without diabetes were assigned to Group 1, subjects with diabetes without retinopathy to Group 2, and people with diabetic retinopathy to Group 3; a researcher recorded diabetes duration, treatments received, and the presence of systemic arterial hypertension, and measured the best corrected visual acuity in all the subjects, using Snellen equivalents. Another researcher obtained an eye fundus photograph with a non-mydriatic camera (Canon, Japan), which a third researcher (a retina specialist) evaluated to grade retinopathy according to the early treatment diabetic retinopathy study criteria. A fourth researcher acquired optical coherence angiotomography images, using the Cirrus 5000a device (Zeiss, Meditec, Dublin, CA), with the following characteristics: a $6 \mathrm{~mm}$ retinal thickness macular cube and a $3 \times 3 \mathrm{~mm}$ angiogram of the superficial capillary plexus, obtained through the automatic segmentation algorithm of the equipment; image quality controls included a correct foveal centering, the absence of artifacts (eyelashes, movement, or any other artifact) that blocked the OCTA signal, and a signal strength $>7$.

Data of the parafoveal vessel density were obtained in each subject and measured by regions as follows: at the periphery of the millimeter concentric to the fovea (central vessel density), within 0.5-1.5 mm from the foveal center (inner vessel density), and in the entire $3 \mathrm{~mm}$ diameter region concentric to the fovea (complete vessel density). The equipment measured the area, perimeter, diameter, and circularity of the foveal avascular zone as well; the equipment calculated all variables automatically, including circularity. 
Table 1. Comparison of general variables characteristics between groups

\begin{tabular}{lcccc}
\hline Variables & Group 1 $\mathbf{( n = 2 0 )}$ & Group 2 (n= 34) & Group 3 (n= 23) & $\mathbf{p}$ \\
\hline Age & $55.70 \pm 12.79$ & $55.67 \pm 6.03$ & $56.65 \pm 9.18$ & $0.86^{*}$ \\
Female gender & $40 \%$ & $58.8 \%$ & $73.9 \%$ & $0.07^{* *}$ \\
Diabetes duration & - & $7.08 \pm 5.22$ & $14.95 \pm 7.57$ & $0.002^{* * *}$ \\
Oral hypoglycemic treatments & - & $94.2 \%$ & $76.9 \%$ & $0.38^{* *}$ \\
Systemic arterial hypertension & - & $20.6 \%$ & $30.4 \%$ & $0.41^{* *}$ \\
\hline${ }^{*}$ Kruskal-Wallis, ${ }^{* *} \chi^{2},{ }^{* * *}$ Mann-Whitney's U-test. & & &
\end{tabular}

Table 2. Comparison of retinal thickness between groups

\begin{tabular}{lcccc}
\hline Variable & Group 1 $(\mathbf{n}=\mathbf{2 0})$ & Group 2 $(\mathbf{n}=\mathbf{3 4})$ & Group 3 $(\mathbf{n}=\mathbf{2 3})$ & $\mathbf{p}^{*}$ \\
\hline CFT (field 1) $(\mu \mathrm{m})$ & $260.55 \pm 17.52$ & $253.97 \pm 16.88$ & $243.35 \pm 22.93$ & 0.01 \\
Field 2 $(\mu \mathrm{m})$ & $316.75 \pm 16.68$ & $322.62 \pm 14.61$ & $317.39 \pm 16.74$ & 0.36 \\
Field3 $(\mu \mathrm{m})$ & $305.00 \pm 14.27$ & $308.85 \pm 15.37$ & $302.78 \pm 21.21$ & 0.62 \\
Field $4(\mu \mathrm{m})$ & $314.55 \pm 17.05$ & $316.03 \pm 15.31$ & $311.78 \pm 17.99$ & 0.66 \\
Field 5 $(\mu \mathrm{m})$ & $320.00 \pm 18.40$ & $325.00 \pm 15.25$ & $316.30 \pm 19.15$ & 0.26 \\
Field 6 $(\mu \mathrm{m})$ & $274.15 \pm 15.54$ & $280.68 \pm 12.28$ & $284.30 \pm 10.87$ & 0.08 \\
Field $7(\mu \mathrm{m})$ & $261.70 \pm 13.91$ & $263.62 \pm 13.24$ & $270.69 \pm 14.03$ & 0.10 \\
Field $8(\mu \mathrm{m})$ & $260.00 \pm 14.49$ & $265.68 \pm 13.16$ & $267.26 \pm 11.80$ & 0.32 \\
Field 9 $(\mu \mathrm{m})$ & $288.75 \pm 17.09$ & $297.18 \pm 15.02$ & $296.35 \pm 13.28$ & 0.21 \\
Macular volume $\left(\mathrm{mm}^{3}\right)$ & $9.91 \pm 0.50$ & $10.09 \pm 0.44$ & $10.10 \pm 0.39$ & 0.46 \\
\hline${ }^{*}$ Kruskal-Wallis, CFT: center field thickness. & & &
\end{tabular}

\section{Statistical analysis}

Means of the angiotomographic variables were compared between the groups using Kruskal-Wallis's test and Mann-Whitney's U-test; correlations between circularity, foveal avascular zone, and parafoveal vessel density were obtained by Spearman's Rho test. $p<0.05$ was considered significant; all the data were stored and analyzed with the SPSS version 22 software, for Windows.

\section{Results}

We evaluated 77 eyes of 52 subjects with an aged man mean 55.90, SD $\pm 9.0,45$ eyes were from females (58.4\%); 57 eyes were from subjects with diabetes, which had a duration of 1 month-25 years $(10.43 \pm 73.8), 22$ of them $(73.3 \%)$ received oral hypoglycemic treatments. 14 eyes were of subjects with systemic arterial hypertension (36.8\%); Group 1 had 20 eyes, Group 2 had 34 eyes, and Group 3 had 23 eyes. Table 1 shows the comparison of the general variables between groups.
Diabetic retinopathy in Group 3 was mild in 13 cases and moderate in 10; central field thickness in the sample was $212-298 \mu \mathrm{m}(252.51 \pm 19.89)$, macular volume was $9.10-10.90 \mathrm{~mm}^{3}(10.05 \pm 0.44)$, and the foveal avascular zone area was $0.05-0.54 \mathrm{~mm}^{2}(0.29 \pm 0.11)$. Table 2 presents the comparison of retinal thickness between groups.

The central vessel density mean was higher in Group 1 than in Group 2 and higher in Group 2 than in Group 3; the inner and complete vessel densities were also higher in Group 2 than in Group 3. The foveal avascular zone area mean was lower in Group 1 than in Group 2, and in Group 2 the means of the area, perimeter, and diameter of the foveal avascular zone were lower than in Group 3; the circularity showed no difference between the groups (Table 3).

In the sample, the circularity had a low positive correlation with the inner vessel density (Rho $=0.35, p=0.002)$ and with the complete vessel density ( $R$ ho $=0.33, p=0.004)$. These correlations did not appear either in Group 1 (Rho $=0.42, p=$ 
Table 3. Comparison of vessel density and foveal avascular zone, between groups

\begin{tabular}{|c|c|c|c|c|}
\hline Variable & Group $1(n=20)$ & Group $2(n=34)$ & Group $3(n=23)$ & $p$ \\
\hline Central vessel density & $11.69 \pm 2.60$ & $9.32 \pm 2.46$ & $7.00 \pm 2.07$ & $<0.001$ \\
\hline Inner vessel density & $21.11 \pm 2.29$ & $20.78 \pm 1.52$ & $19.90 \pm 1.80$ & 0.06 \\
\hline Complete vessel density & $20.06 \pm 2.11$ & $19.49 \pm 1.53$ & $18.45 \pm 1.73$ & 0.01 \\
\hline \multicolumn{5}{|l|}{ Foveal avascular zone } \\
\hline Area & $0.22 \pm 0.10$ & $0.28 \pm 0.09$ & $0.38 \pm 0.10$ & $<0.001$ \\
\hline Perimeter & $2.03 \pm 0.48$ & $2.29 \pm 0.39$ & $2.77 \pm 0.47$ & $<0.001$ \\
\hline Diameter & $0.65 \pm 0.15$ & $0.73 \pm 0.13$ & $0.88 \pm 0.15$ & $<0.001$ \\
\hline Circularity & $0.65 \pm 0.06$ & $0.65 \pm 0.10$ & $0.61 \pm 0.10$ & 0.27 \\
\hline
\end{tabular}

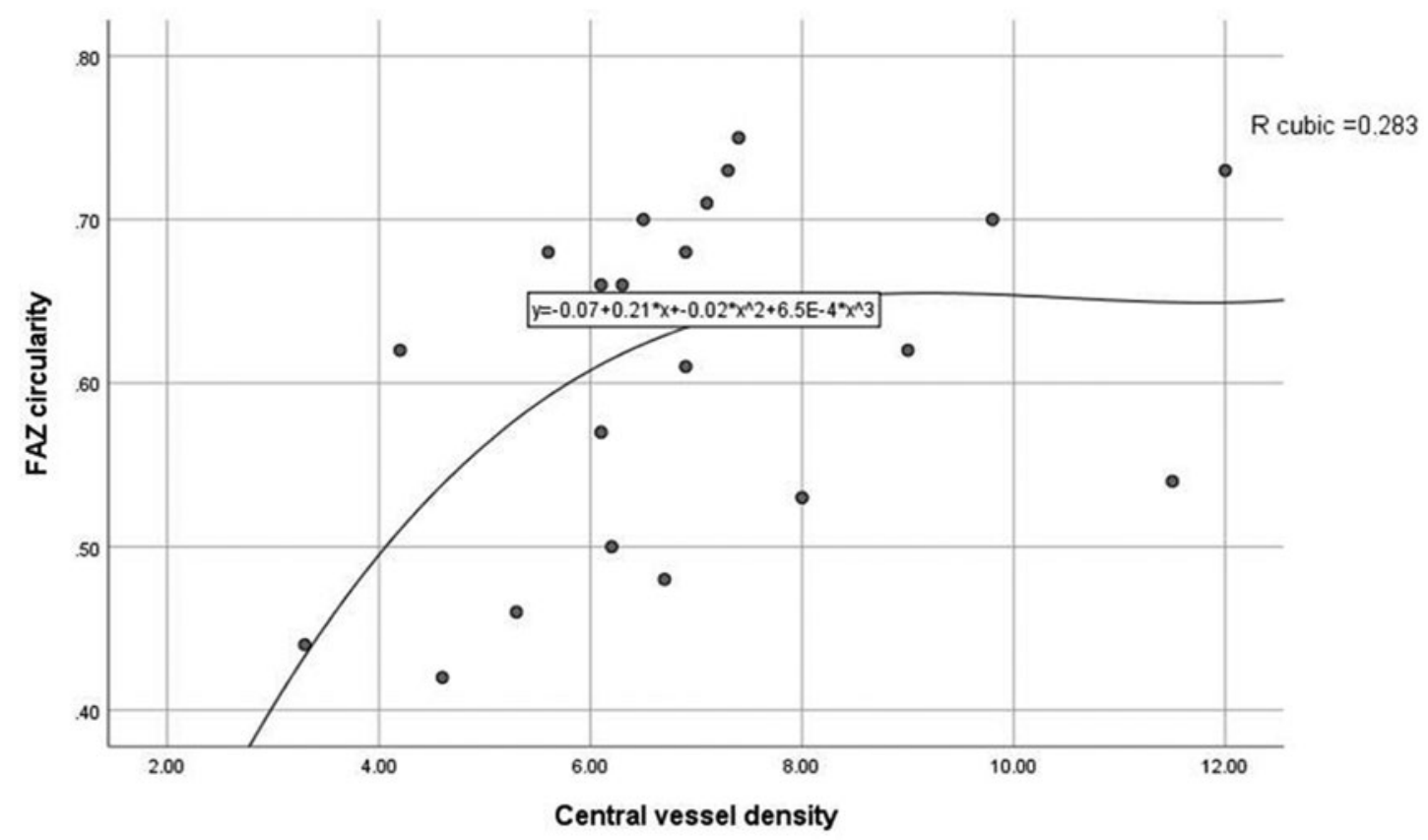

Figure 1. Cubic correlation between central vessel density and foveal avascular zone circularity, in subjects with diabetic retinopathy.

0.37 ) or in Group 2 (Rho = 0.03, p = 0.23); in Group 3, the circularity had a correlation with the central vessel density (Rho $=0.45, p=0.03$ ), with the inner vessel density (Rho $=0.56, p=0.005)$, and with the complete vessel density (Rho $=0.53, p=0.009$ ) (Figs. 1 and 2). There was no correlation between the circularity and the area, the perimeter or the diameter of the foveal avascular zone, either in the sample or in each group.

\section{Discussion}

The mean circularity of the foveal avascular zone in subjects without diabetes was 0.65 , which did not differ from that found in subjects with diabetes, with and without retinopathy. The circularity and parafoveal vessel density had no correlation either in subjects without diabetes or in subjects with diabetes with no retinopathy; these variables had a low correlation in people with diabetic retinopathy.

Circularity in subjects without diabetes was lower than that reported with other OCTA devices, which produced $0.81 \pm 0.07^{11}$, and did not differ from that found with the same equipment in other populations. Kim et al. had reported that there was no difference between mean circularity of subjects without diabetes and people with diabetes without retinopathy and that the mean in subjects with retinopathy was lower ${ }^{12}$.

Krawitz et al. and his group ${ }^{13}$ reported that circularity means did not change between subjects with diabetes without retinopathy and people with retinopathy; Lee 


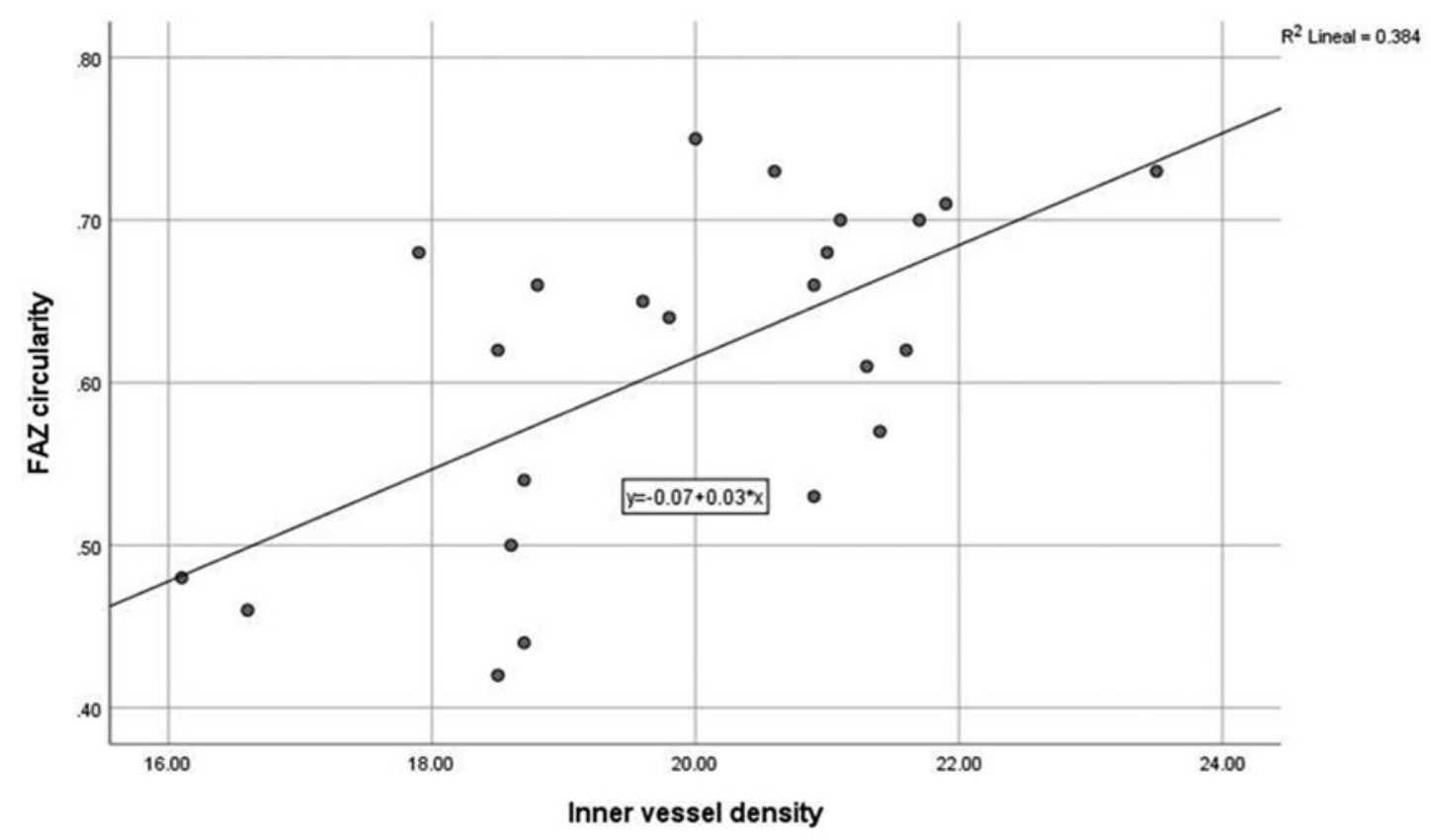

Figure 2. Linear correlation between inner vessel density and the foveal avascular zone circularity, in subjects with diabetic retinopathy.

et al. ${ }^{14}$, also found no difference between these groups and reported a higher circularity means in subjects with mild non-proliferative retinopathy compared with subjects without diabetes. The circularity means did not change between groups in our study, probably because it only evaluated cases whose foveal avascular zone area did not suggest ischemia.

Fluorescein angiography is more sensitive to detect early retinopathy, but it is a time-consuming invasive method, which is not appropriate as a test to find preclinical changes ${ }^{15}$; one study found that acircularity measurements (another method of evaluating circularity) were comparable between optical coherence angiotomography and fluorescein angiography with scanning ophthalmoscopy ${ }^{16}$.

Although the foveal avascular zone did not present characteristics of ischemia, its size increased in subjects with retinopathy, which indicates damage to the parafoveal capillary network. Parafoveal vessel density in the central region decreased in subjects with diabetes compared with subjects without diabetes, and this decrease was more marked in subjects with retinopathy. Even though vessel density decreased, it was not enough to alter the circularity in subjects with diabetic retinopathy.

The correlation between the circularity and the inner vessel density in people with retinopathy was low, and the regression analysis identified a better fit with a cubic model. A steep circularity change was observed with a low vessel density, but the plateau effect that occurred in a range of densities suggests that the most common stages of diabetic retinopathy do not modify the circularity; this variable had a higher positive correlation with the foveal avascular zone area in people with retinopathy than in the other groups, which would indicate that its alterations appear with more advanced stages of retinopathy, where ischemia exists.

One strength of the study is that we only evaluated subjects without foveal ischemic features, which reduced the dispersion of the variables in people with retinopathy; another one was working with the superficial capillary plexus, whose vascular supply is mainly arterial ${ }^{17}$, has a standardized measurement, and is better to reveal ischemia data than the deep capillary plexus ${ }^{18}$. In addition, retinal thickness was normal, which prevented vessel density values from distorting due to measuring at different levels, as it can occur in eyes with a retinal thickening. One potential limitation is that the low number of subjects in each retinopathy level restricted a regression analysis between circularity and parafoveal vessel density; the correlation between these variables had not been described, and it will be convenient to analyze it in further studies, to identify a cutoff point for changes of circularity in eyes with retinopathy. 
Alterations in the circularity, according to the findings of this study, appear later than the reduction of parafoveal vessel density; in diabetic people, without retinopathy, a normal circularity, as well as a foveal avascular area of normal size, would not indicate that the parafoveal capillary network is healthy. The circularity of the foveal avascular zone does not add information in eyes with mild and moderate diabetic retinopathy when the parafoveal vessel density can be identified nor could it anticipate by itself a decrease in vessel density, when this variable cannot be appropriately measured.

\section{Conflicts of interest}

The authors declare that there are no conflicts of interest.

\section{Funding}

The author(s) received no specific funding for this work.

\section{Ethical disclosures}

Protection of human and animal subjects. The authors declare that the procedures followed were in accordance with the regulations of the relevant clinical research ethics committee and with those of the Code of Ethics of the World Medical Association (Declaration of Helsinki).

Confidentiality of data. The authors declare that they have followed the protocols of their work center on the publication of patient data.

Right to privacy and informed consent. The authors have obtained the written informed consent of the patients or subjects mentioned in the article. The corresponding author is in possession of this document.

\section{References}

1. Hammes HP, Lemmen KD, Bertram B, German Diabetes Association. Diabetic retinopathy and maculopathy. Exp Clin Endocrinol Diabetes. 2014;122:387-90.

2. Liew G, Michaelides M, Bunce C. A comparison of the causes of blindness certifications in England and Wales in working age adults (1664 years), 1999-2000 with 2009-2010. BMJ Open. 2014;4:e004015.

3. Zhang X, Zeng H, Bao S, Wang N, Gillies MC. Diabetic macular edema: new concepts in patho-physiology and treatment. Cell Biosci. 2014; 4:27.

4. Holekamp NM, Campbell J, Almony A, Ingraham H, Marks S, Chandwani $\mathrm{H}$, et al. Vision outcomes following anti-vascular endothelial growth factor treatment of diabetic macular edema in clinical practice. Am J Ophthalmol. 2018;191:83-91.

5. Couturier A, Mané V, Bonnin S, Erginay A, Massin P, Gaudric A, et al. Capillary plexus anomalies in diabetic retinopathy on optical coherence tomography angiography. Retina. 2015;35:2384-91.

6. Sim DA, Keane PA, Zarranz-Ventura J, Fung S, Powner MB, Platteau E, et al. The effects of macular ischemia on visual acuity in diabetic retinopathy. Invest Ophthalmol Vis Sci. 2013;54:2353-60.

7. Liew G, Sim DA, Keane PA, Tan AG, Mitchell P, Wang JJ, et al. Diabetic macular ischaemia is associated with narrower retinal arterioles in patients with Type 2 diabetes. Acta Ophthalmol. 2015;93:e45-51.

8. Soares M, Neves C, Marques IP, Pires I, Schwartz C, Costa MÂ, et al. Comparison of diabetic retinopathy classification using fluorescein angiography and optical coherence tomography angiography. Br J Ophthalmol. 2017;101:62-8.

9. Rosenfeld PJ, Durbin MK, Roisman L, Zheng F, Miller A, Robbins G, et al. ZEISS angioplex ${ }^{\mathrm{TM}}$ spectral domain optical coherence tomography angiography: technical aspects. Dev Ophthalmol. 2016;56:18-29.

10. Di G, Weihong Y, Xiao Z, Zhikun Y, Xuan Z, Yi Q, et al. A morphological study of the foveal avascular zone in patients with diabetes mellitus using optical coherence tomography angiography. Graefes Arch Clin Exp Ophthalmol. 2016;254:873-9.

11. Choi J, Kwon J, Shin JW, Lee J, Lee S, Kook MS, et al. Quantitative optical coherence tomography angiography of macular vascular structure and foveal avascular zone in glaucoma. PLoS One. 2017:12:e0184948.

12. Kim K, Kim ES, Yu SY. Optical coherence tomography angiography analysis of foveal microvascular changes and inner retinal layer thinning in patients with diabetes. Br J Ophthalmol. 2017;102:1226-31.

13. Krawitz BD, Mo S, Geyman LS, Agemy SA, Scripsema NK, Garcia PM, et al. Acircularity index and axis ratio of the foveal avascular zone in diabetic eyes and healthy controls measured by optical coherence tomography angiography. Vision Res. 2017;139:177-86.

14. Lee H, Lee M, Chung H, Kim HC. Quantification of retinal vessel tortuosity in diabetic retinopathy using optical coherence tomography angiography. Retina. 2018;38:976-85.

15. Coscas G, Lupidi M, Coscas F, Chhablani J, Cagini C. Optical coherence tomography angiography in healthy subjects and diabetic patients. Ophthalmologica. 2018;239:61-73.

16. Mo S, Krawitz B, Efstathiadis E, Geyman L, Weitz R, Chui TY, et al. Imaging foveal microvasculature: optical coherence tomography angiography versus adaptive optics scanning light ophthalmoscope fluorescein angiography. Invest Ophthalmol Vis Sci. 2016;57:OCT130-40.

17. Gass JD. Stereoscopic Atlas of Macular Diseases. St. Louis: Mosby; 1997.

18. Durbin MK, An L, Shemonski ND, Soares M, Santos T, Lopes M, et al. Quantification of retinal microvascular density in optical coherence tomographic angiography images in diabetic retinopathy. JAMA Ophthalmol. 2017:135:370-6 